\title{
Distribusi Dan Karakter Situs-Situs Neolitik Di Kecamatan Bantarkalong Dan Karangnunggal, Tasikmalaya, Jawa Barat
}

\section{Retno Handini}

Keywords: pattern, distribution, neolithic, workshop, prehistory, spatial, area

\section{How to Cite:}

Handini, R. (1999). Distribusi Dan Karakter Situs-Situs Neolitik Di Kecamatan Bantarkalong Dan Karangnunggal, Tasikmalaya, Jawa Barat. Berkala Arkeologi, 19(2), 14-21. https://doi.org/10.30883/jba.v19i2.819

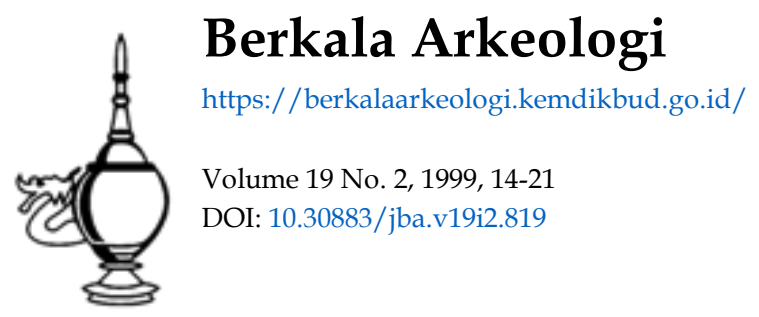

\section{(†)(2)}

This work is licensed under a Creative Commons Attribution-NonCommercial-ShareAlike 4.0 International License. 


\title{
DISTRIBUSI DAN KARAKTER SITUS-SITUS NEOLITIK DI KECAMATAN BANTARKALONG DAN KARANGNUNGGAL, TASIKMALAYA, JAWA BARAT
}

\author{
Retno Handini \\ (Pusat Penelitian Arkeologi Nasional)
}

\section{A. Pendahuluan}

Masa bercocok tanam di Indonesia dimulai kira-kira bersamaan dengan berkembangnya kemahiran mengupam alat-alat batu serta mulai dikenalnya teknologi pembuatan gerabah (Soejono, 1984). Data artefaktual dari masa ini yang terdefinisi dalam konteks teknologi neolitik antara lain berupa beliung persegi, batu asah, gerabah, gelang dan cincin dari berbagai jenis batuan, manik-manik serta pemukul kulit kayu (Heekeren, 1972). Kehidupan manusia pada masa tersebut menunjukkan penguasaan dan pemanfaatan alam untuk memenuhi kebutuhan hidup yang telah maju dengan pesat. Pengupaman (polishing) dalam teknologi alat batu merupakan unsur baru dan telah dikembangkan secara baik, dibandingkan dengan pemangkasan (chipping) dan penyerpihan (flaking) dari tingkatan teknologi sebelumnya. Akibatnya, pembuatan alat-alat batu menunjukkan peningkatan kemahiran, sehingga menghasilkan benda-benda yang lebih sempurna dari sesuai dengan tujuan pemakaiannya.

Pengetahuan tentang masa bercocok tanam di Indonesia sebenarnya masih sangat terbatas karena data-data arkeologi belum terungkap secara lengkap. Beberapa temuan yang berasal dari budaya neolitik dari hasil penelitian baik survei maupun ekskavasi masih sangat sedikit jumlahnya, di antaranya berasal dari beberapa tempat di Pulau Jawa dan Sulawesi, dan temuan lepas yang berhasil dikumpulkan dari hasil survei permukaan dan pembelian dari penduduk (Soejono, 1984). Dari beberapa temuan lepas tersebut, maka dapat diketahui daerah persebaran alat-alat dari hasil budaya neolitik di Indonesia, diantaranya terdapat di Sumatera (Bengkulu, Palembang, Lampung), Jawa (Banten, Bogor, Cibadak, Cirebon, Bandung, Tasikmalaya, Pekalongan, Banyumas, Purbalingga, Semarang, Kedu, Yogyakarta, Wonogiri, Pacitan, Surabaya, Madura, Malang dan Besuki), Kalimantan, Sulawesi, Bali, Solor, Adonara, Maluku, Sangihe dan Talaud (Heekeren, 1972). Diantara tempat-tempat tersebut terdapat beberapa situs yang diperkirakan sebagai bengkel-bengkel tempat pembuatan alat-alat neolitik, antara lain yaitu di Desa Bungamas (dekat Palembang), Desa Pasirkuda (Bogor), daerah Pegunungan Karangbolong di dekat Karanganyar (Kedu), Punung (Pacitan), Limbasari dan Ponjen (Purbalingga), serta Karangnunggal (Tasikmalaya). 
Informasi tentang temuan unsur budaya neolitik di Tasikmalaya pertama kali dikemukakan oleh H.R. Van Heekeren dalam bukunya "The Stone Age of Indonesia". Dalam buku tersebut disebutkan bahwa di daerah dekat Tasikmalaya di Jawa Barat ditemukan banyak batu-batu terupam halus yang digunakan sebagai bahan untuk membuat perhiasan (gelang) yang dibuat dari batu-batu pilihan seperti agat, kalsedon, jaspis berwarna putih, kuning, coklat, merah dan hijau. Daerah ini diperkirakan sebagai pusat kegiatan (perbengkelan) pembuatan beliung persegi dari masa neolitik.

Pada sekitar tahun 1980-an Pusat Penelitian Arkeologi Nasional pernah mengadakan peninjauan terhadap beberapa lokasi di Tasikmalaya yang diperkirakan pernah menjadi situs-situs bengkel neolitik, namun sayang sekali dari hasil laporan tersebut tidak diketahui secara jelas keberadaan situs-situs tersebut. Berangkat dari situasi tersebut, pada tahun 1998, Bidang Prasejarah Pusat Penelitian Arkeologi Nasional kembali mengadakan penelitian di Tasikmalaya untuk mengetahui sebaran tinggalantinggalan dari budaya neolitik di wilayah ini melalui tinjauan eksploratif.

\section{B. Distribusi Situs-Situs Neolitik di Kecamatan Bantarkalong dan Karangnunggal}

Kabupaten Tasikmalaya secara fisiografi berada pada jalur pegunungan selatan (Bemmelen, 1949). Zona ini merupakan zona yang mengalami proses pengangkatan yang cukup kuat pada Kala Miosen dan dinamakan pula sebagai Karangnunggal section yang setara dengan Jampang section di bagian barat dari Jawa Barat (Djubiantono, 1998). Morfologi penelitian merupakan suatu perbukitan bergelombang dan dataran, umumnya didominasi oleh berbagai tanaman keras dan palawija di beberapa tempat. Dari hasil penelitian tahun 1998, ditemukan beberapa situs prasejarah di Kecamatan Bantarkalong dan Karangnunggal, yaitu :

\section{Situs Kiarakoneng 1, Desa Girijaya, Kecamatan Bantarkalong}

Situs ini merupakan daerah lereng perbukitan dengan sudut kemiringan lereng sekitar $20^{\circ}-30^{\circ}$, yang terletak pada posisi $106^{\circ} 56^{1} 20,59^{11}$ BT dan $7^{\circ} 34^{1} 14,40^{11} \mathrm{LS}$, meredian Jakarta. Situs yang berada pada ketinggian $320 \mathrm{~m}$ di atas permukaan air laut ini terletak $\pm 300 \mathrm{~m}$ di sebelah timur pertemuan Sungai Cilangla dan Sungai Cilumping. Tingkat erosi situs cukup tinggi dengan lapisan budaya yang tipis. Alatalat neolitik umumnya ditemukan di lereng-lereng tegalan, antara lain bahan dasar, perkutor, batu bulat, bahan gelang, calon beliung kecil serta serpihan.

\section{Situs Kiarakoneng 2, Desa Girijaya, Kecamatan Bantarkalong}

Situs ini berjarak $\pm 350 \mathrm{~m}$ sebelah tenggara Situs Kiarakoneng 1, sekitar $400 \mathrm{~m}$ sebelah timur sungai Cilangla, yang berada pada ketinggian $320 \mathrm{~m}$ di atas permukaan air laut, dan berada di lereng perbukitan dengan kemiringan lereng $15^{\circ}-20^{\circ}$. Beberapa 
artefak neolitik berhasil ditemukan, antara lain berupa perkutor, calon beliung, bahan beliung, fosil kayu, serpihan, dan batuan jasper.

\section{Situs Cikumpul, Desa Parakanhonje, Kecamatan Bantarkalong}

Situs ini merupakan tegalan yang berada di daerah perbukitan dengan ketinggian sekitar $330 \mathrm{~m}$ di atas permukaan air laut, terletak $\pm 400 \mathrm{~m}$ sebelah barat jalan desa Cikumpul, pada KM 4,25 dari Simpang Bantarkalong. Jarak Situs Cikumpul ke Sungai Cilangla sekitar $2 \mathrm{~km}$. Informasi mengenai situs ini diperoleh dari penduduk desa setempat yang menyimpan beberapa artefak neolitik yakni calon gelang dan bahan gelang yang ditemukan pada waktu mencangkul sawah sekitar tahun 1994. Namun sayangnya hasil survei yang dilakukan di situs ini hanya menemukan beberapa serpihan dan batuan kalsedon.

\section{Situs Cihandiwung, Desa Parakanhonje, Kecamatan Bantarkalong}

Situs Cihandiwung terletak di pinggir jalan raya pada KM 8,5 dari Simpang Bantarkalong, dan hanya berjarak sekitar $500 \mathrm{~m}$ sebelah selatan Situs Kiarakoneng 2. Situs ini merupakan daerah aliran sungai Cilangla yang termasuk sungai berstadia dewasa, pada ketinggian sekitar $290 \mathrm{~m}$ di atas permukaan laut. Di sepanjang aliran sungai ini banyak ditemukan alat-alat paleolitik seperti serut samping, serut gigir, serpih tanpa retus, kapak perimbas, "pick", dan sebuah lancipan yang nampaknya berasal dari budaya neolitik.

\section{Situs Leuwitere, Desa Parakanhonje, Kecamatan Bantarkalong}

Situs Leuwitere juga berada di daerah aliran Sungai Cilangla, lebih ke arah hilir dibandingkan dengan Situs Cihandiwung pada jarak sekitar $6 \mathrm{~km}$, dengan ketinggian $290 \mathrm{~m}$ di atas permukaan laut. Selain alat-alat paleolitik pada situs ini ditemukan juga alat neolitik berupa calon-calon beliung. Alat-alat paleolitik yang ditemukan antara lain berupa serut ujung, kapak perimbas, batu inti, serut berpunggung tinggi, dan serpih. Situs Leuwitere lebih padat temuannya dibandingkan Situs Cihandiwung.

\section{Situs Madur, Desa Bojongasih, Kecamatan Bantarkalong}

Situs ini merupakan daerah dataran yang diapit oleh 3 perbukitan yaitu Bukit Seueur di sebelah timur yang berjarak $\pm 30 \mathrm{~m}$, dan Gunung Kerud di sebelah selatan pada jarak $\pm 1,2 \mathrm{~km}$, dengan ketinggian $310 \mathrm{~m}$ di atas permukaan laut. Saat ini situs tersebut dimanfaatkan sebagai tempat pemakaman umum. Tidak jauh dari situs ini, \pm $2 \mathrm{~km}$ di sebelah barat dayanya, terdapat Sungai Cimadur yang bermuara di Sungai Cilangla. Survei di situs ini berhasil menemukan sejumlah artefak berupa calon beliung, calon beliung kecil, bahan gelang, perkutor, dan serpihan. Persebaran artefak cukup luas, karena artefak-artefak tersebut tidak hanya ditemukan di areal kuburan saja, melainkan juga di daerah sekitarnya yang saat ini digunakan sebagai lokasi pabrik tapioka. 


\section{Situs Karangsari, Desa Karangnunggal, Kecamatan Karangnunggal}

Situs Karangsari terletak $\pm 500 \mathrm{~m}$ di sebelah selatan Sungai Ciarus yang bermuara di Sungai Cilangla, dengan koordinat $106^{\circ} 57^{1} 13,97^{11}$ BT dan $7^{0} 37^{P} 13,68^{11}$ LS, meredian Jakarta, pada ketinggian $300 \mathrm{~m}$ di atas permukaan air laut. Hasil survei di situs ini berhasil memperoleh sejumlah artefak berupa bahan gelang, batu inti, calon beliung dan serpihan.

\section{Karakter Teknologis}

\section{Calon beliung}

Calon beliung umumnya masih dalam tahap pembentukan, namun sudah berbentuk persegi panjang, dengan bagian tajaman lebih lebar dari bagian pangkal. Bahan dasarnya adalah jasper dan kalsedon, dengan variasi ukuran panjang antara 9-12 cm, lebar 4-5 cm, dan tebal antara $1-2,5 \mathrm{~cm}$. Beberapa calon beliung ada yang seluruh permukaannya sudah rata dan halus, dan hanya membutuhkan proses pengupaman, sementara beberapa calon beliung lain masih dalam tahap pembentukan ke arah bentuk segi empat. Dalam kasus terakhir, seluruh permukaan alat didominasi oleh pangkasan primer melalui pemangkasan melebar, sehingga meninggalkan bulbusbulbus negatif berukuran besar. Arah pangkasan pada kedua permukaan alatnya dilakukan secara transversal dari kedua sisi lateral, sementara pada bagian sisi-sisinya dilakukan secara vertikal. Rata-rata calon beliung telah mengalami pembundaran, hal ini menunjukkan adanya transportasi alat ini dari tempat aslinya.

\section{Beliung}

Beliung yang ditemukan umumnya sudah berbentuk persegi dengan ketebalan yang belum merata dan tidak beraturan. Beda dengan calon beliung adalah pada bagian tajaman yang telah dibentuk melalui pemangkasan melandai dan diikuti dengan penggosokan di bagian tersebut. Pada salah satu permukaannya, biasanya telah rata dan halus yang dihasilkan melalui satu pangkasan sedangkan bidang yang lain masih tertutup korteks batuan. Sebagian lagi menampakkan adanya bekas-bekas pangkasan. Pada umumnya beliung dibuat dari chert, kalsedon dan jasper dengan ukuran panjang antara 8-15 cm, lebar antara 6-9 cm, dan tebal antara $3-5 \mathrm{~cm}$.

Dalam kategori teknologis beliung ini, juga ditemukan sejumlah beliung berukuran kecil, dengan panjang antara $3-4 \mathrm{~cm}$, lebar $2-3 \mathrm{~cm}$, san tebal $0.8-2 \mathrm{~cm}$, dari bahan dasar kalsedon dan chert. Umumnya sudah berbentuk persegi dengan permukaan yang rata dan meninggalkan bekas-bekas pangkasan. Beberapa artefak ini sudah membentuk beliung jadi, dengan kedua permukaan yang sudah rata, dan hanya tinggal dilakukan pengupaman untuk menghaluskannya. 


\section{Bahan gelang}

Bahan gelang yang ditemukan hampir semuanya berbentuk bulat dan bulat gepeng, dibuat dari batuan chert, agat dan kalsedon. Ukurannya bervariasi dengan diameter antara 5-7 cm dan tebal sekitar $2 \mathrm{~cm}$. Kedua permukaan umumnya sudah rata dan dibentuk melalui pemangkasan-pemangkasan, sedangkan permukaan sisinya dibentuk melalui pemangkasan vertikal. Dilihat dari faset-faset penyerpihan pada permukaannya, tampaknya bahan-bahan gelang ini telah mengalami tahap pemangkasan penghalusan, ke arah penyiapan bahan dalam bentuk benda pipih, sebelum dilakukan penggosokan pada seluruh permukannya. Hal ini didasarkan pada ukuran faset, yang cenderung berukuran kecil dan halus, sebagai akibat dari penyerpihan tidak langsung (indirect-percussion). Kulit batu umumnya masih tersisa pada permukaan alat. Sebuah bahan gelang dari Cikumpul masih menunjukkan permukaan yang lebih kasar akibat pemangkasan primer melebar, yang mengindikasikan tingkat pembentukan awal. Beberapa bahan gelang ada yang berbentuk setengah lingkaran dengan sebagian permukaan yang berbentuk cembung dan menyisakan korteks batuan. Nampaknya batuan ini sudah disiapkan menjadi bahan gelang, namun dalam pengerjaannya mengalami kerusakan (pecah).

\section{Gelang}

Gelang umumnya dibuat dari bahan batuan kalsedon berbentuk bulat dengan kedua permukaan datar, bagian permukaan gelang ini umumnya sudah mengalami penggosokan berdasarkan striasi-striasi yang tampak memenuhi permukaannya dan belum diupam. Pola-pola striasi menunjukkan penggosokkan ke segala arah. Diameter gelang berkisar antara 7-10 cm, dengan diameter lubang antara $4-8 \mathrm{~cm}$ dan tebal gelang antara $1,5-2 \mathrm{~cm}$.

\section{Perkutor}

Perkutor dibuat dari bahan kalsedon, rijang dan fosil kayu. Umumnya berbentuk membulat dengan permukaan yang cenderung rata. Di sekitar permukaan batuan terdapat luka-luka pukul, pada bagian proksimal salah satu perkutor terdapat luka pukul yang cukup besar. Perkutor ini mempunyai diameter sekitar $10 \mathrm{~cm}$, dengan ketebalan sekitar 4-7 cm.

\section{Serpihan}

Umumnya serpihan terbuat dari bahan chert dan kalsedon, dengan bentuk yang tidak beraturan. Ukurannya cukup bervariasi, panjang antara $2-5 \mathrm{~cm}$, lebar antara : $2-5 \mathrm{~cm}$ dan tebal antara : $0,1-2 \mathrm{~cm}$. Salah satu serpihan tersebut pada bagian distalnya terdapat retus yang memanjang dan bersambung. Satu serpihan lainnya masih tertutup korteks dengan satu permukaan rata dan lainnya cembung. Bulbus rata-rata menonjol dan terdapat dataran pukul. Hampir pasti, serpihan-serpihan tersebut merupakan limbah produksi dari pembuatan gelang maupun beliung persegi. 


\section{Fosil kayu}

Temuan lain dari situs ini yakni fossil kayu yang berbentuk persegi dan bulat lonjong, dengan permukaan yang sangat halus dan nampak ada bekas-bekas pengupaman. Panjang 4,5 cm 4,5 cm, lebar : $1,2 \mathrm{~cm}$, dan tebal $1 \mathrm{~cm}$.

\section{Batuan}

Batuan ini terbuat dari bahan jasper dan kalsedon. Bentuknya tidak beraturan, salah satu permukaannya terdapat beberapa pangkasan, sedangkan permukaan lain masih mengandung korteks. Karena pengerjaannya yang masih awal, tipologi alat ini tidak bisa diketahui. Ukuran panjang antara 7,5-8,5 cm, lebar sekitar $5 \mathrm{~cm}$ dan tebal sekitar $4 \mathrm{~cm}$.

\section{Calon pahat}

Bentuk persegi panjang, terbuat dari bahan jasper, berwarna merah. Kedua permukaan sudah rata dan meninggalkan bekas-bekas pangkasan. Bagian distal lebih lebar dari bagian proksimal. Ukuran panjang: $15 \mathrm{~cm}$, lebar: $3 \mathrm{~cm}$ dan tebal: $1,5 \mathrm{~cm}$.

\section{Penutup}

Artefak-artefak yang ditemukan di Kecamatan Bantarkalong dan Karangnunggal di atas terutama dicirikan oleh teknologi neolitik, antara lain berupa calon beliung, beliung jadi, bahan gelang, dan gelang. Bahan dasar pembuatan artefak tersebut adalah batuan berkadar silika tinggi, terdiri atas kalsedon, chert, agat, dan jasper. Kuantitas dan kualitas artefak yang berhasil dikumpulkan menunjukkan potensi arkeologis tingkatan teknologi neolitik yang cukup tinggi di kecamatan tersebut. Situs Cikumpul merupakan daerah perbengkelan gelang batu, situs Kiarakoneng 1 dan Kiarakoneng 2 merupakan daerah perbengkelan beliung, situs Madur dan Karangsari merupakan daerah perbengkelan beliung dan gelang batu, sedangkan situs Leuwitere dan Cihandiwung merupakan situs-situs yang mengandung temuan artefak-artefak neolitik dan paleolitik.

Melihat jenis temuan yang cukup lengkap tahapan-tahapan teknologinya, mulai dari bahan, calon gelang, gelang yang sudah jadi, hingga ke serpih-serpih bekas pemangkasannya, maka situs-situs Madur dan Karangsari dapat dikatakan sebagai situs-situs perbengkelan pembuatan gelang-gelang batu. Gelang-gelang yang ditemukan umumnya terbuat dari bahan kalsedon, berwarna putih dan kecoklatan. Gelang maupun calon gelang, ukurannya bervariasi. Dilihat dari ukurannya, gelang yang paling kecil mungkin lebih digunakan sebagai benda pusaka atau sebagai antinganting. 
Dari berbagai unsur temuan gelang batu tersebut dapat diketahui cara pembuatannya. Dalam hal ini, Simanjuntak dan Widianto (1990) telah memberikan gambaran sebagai berikut. Langkah pertama adalah penyiapan bahan baku, yang kemudian dibentuk menjadi bahan gelang yang berbentuk bulat dan mempunyai dua bidang datar dengan ketebalan tertentu. Pembentukan dilakukan dengan pemangkasan primer secara langsung, seperti ditunjukkan oleh cekungan-cekungan melebar dan memanjang di seluruh permukaannya. Pengerjaan berikutnya berupa pemangkasan sekunder bahan gelang dari pinggir ke tengah, sehingga menghasilkan bulbus-bulbus negatif berukuran kecil di atas bulbus-bulbus negatif berukuran besar. Pembentukan sisi lingkaran dilakukan dengan pemangkasan vertikal.

Tahap selanjutnya adalah penggosokan seluruh permukaan sebelum dilakukan proses pemboran. Penggosokan ditargetkan untuk menghasilkan permukaan halus di bagian pinggirnya yang menjadi "calon gelang", kemudian dilanjutkan dengan pemboran dua muka. Proses ini akan menghasilkan garis pertemuan melingkar, baik pada fragmen gelangnya maupun pada sisa bahan gelangnya. Berdasarkan striasi-striasi yang terlihat pada bekas-bekas pemboran, maka diketahui bahwa pemboran sering bertahap pada setiap muka.

Semua situs-situs arkeologi yang ada di Daerah Karangnunggal dan Bantarkalong ini terletak tidak jauh dari aliran sungai. Pola aliran sungai umumnya mendaun dengan sungai utamanya yang sedang mengalir saat ini adalah sungai Cilangla yang mengalir ke arah selatan menuju lautan Hindia, dengan anak-anak sungainya antara lain Cilumping dan Ciarus. Sungai-sungai yang ada sangat tergantung pada musim. Pada musim kemarau, debit air tidak begitu banyak sehingga sungai-sungai tersebut umumnya kering dan hanya beberapa saja yang mengandung air. Sebaliknya pada musim penghujan air sangat melimpah.

Pola situs perbengkelan dari budaya neolitik yang terletak tidak jauh dari aliran sungai -dan terutama di Kecamatan Bantarkalong dan Karangnunggal ini beserta karakter teknologis yang melekat pada unsur budayanya-- mengingatkan kita pada situs-situs serupa lainnya seperti situs-situs perbengkelan gelang batu yang ada di daerah Limbasari dan Ponjen (Purbalingga) yang umumnya juga berada di dekat aliran sungai. Hal ini dapat dipahami, karena pada masa itu, sungai memegang peranan sangat penting bagi kehidupan manusia, baik untuk sarana transportasi maupun untuk memenuhi kebutuhan air sehari-hari, sehingga tempat hunian mereka selalu diupayakan untuk dekat dengan sumber air. Apalagi pada masa neolitik, mereka sudah mulai menerapkan cara bercocok tanam, sehingga kebutuhan akan air sangat tinggi. 


\section{KEPUSTAKAAN}

Bemmelen, R.W. van, 1949. The Geology of Indonesia, The Hague : Martinus Nijhoff.

Djubiantono, Tony, 1998. Geologi Daerah Karangnunggal, Kabupaten Tasikmalaya, Provinsi Jawa Barat, Balai Arkeologi Bandung: Laporan Hasil Penelitian Arkeologi, Bandung.

Handini, Retno dan Truman Simanjuntak, 1998. Laporan Penelitian Arkeologi Situs-Situs Neolitik di Kabupaten Tasikmalaya, Provinsi Jawa Barat, Bidang Prasejarah Puslit Arkenas, tidak diterbitkan.

Heekeren, H.R. van, 1972. The Stone Age of Indonesia, Gravenhage : Martinus Nijhoff.

Soejono, R.P., (ed), 1984. Sejarah Nasional Indonesia Jilid I, Jakarta : Balai Pustaka.

Simanjuntak, Truman dan Harry Widianto, 1990. Laporan Penelitian Arkeologi Situs Ponjen, Purbalingga, Jawa Tengah, Berita Penelitian Arkeologi no. 42. Jakarta : Pusat Penelitian Arkeologi Nasional.

Wahyono, W. Dan B. Pardianto, 1993. Hasil Eksplorasi Logam Mulia di Daerah Pegunungan Selatan, Kabupaten Ciamis, Tasikmalaya, Garut, Jawa Barat, Bandung : Proceeding PIT IAGI XXII. 